LEADING ARTICLE

\title{
Gastrointestinal complications of pelvic radiotherapy: are they of any importance?
}

\section{J Andreyev}

Gut 2005;54:1051-1054. doi: 10.1136/gut.2004.062596

Radiation induced bowel damage affects 6000 individuals annually in the UK, with a negative impact on quality of life. Our understanding of how to treat these patients is dismally lacking an evidence base. Fibrosis seems to be the unifying underlying cause for most symptoms. Progress in understanding the development and treatment of fibrosis in these patients might have important consequences for patients with other causes of fibrosis in the gastrointestinal tract

Correspondence to: Dr H J N Andreyev Department of Medicine and Therapeutics, Imperial College Faculty of Medicine, Chelsea and

Westminster Hospital, 369 Fulham Rd, London SW10 9NH, UK;

J@andreyev.demon.co.uk

Revised version received 28 February 2005

Accepted for publication 3 March 2005 t is quite strange why some illnesses become important and others do not. If a new system for supporting research were set up (and it certainly is desperately required in the UK), then the relevance of allocating funds to a specific condition may depend on how common it is, how much morbidity it causes, how much that morbidity costs society at home and internationally, and how likely it is that investigation may lead to progress both for it and for other conditions. Funding would not be allocated under the influence of emotion, lobbyists, because it is politically expedient, to develop unnecessary models of the disease, or when the researcher does not have access to the condition.

Many of the people who read this journal are involved in the treatment of patients with inflammatory bowel disease (IBD). In the UK, a new diagnosis of Crohn's or ulcerative colitis will be made in approximately 7000-13 000 patients this year. ${ }^{12}$ It is not clear how much money in total is available to research every aspect of the management of the disease, but the two main gastrointestinal charities in the UK alone spent approximately half a million pounds on IBD last year. At the British Society of Gastroenterology (BSG) meeting this year, there were 18 hours of discussion and 48 posters directly devoted to IBD. This is only right and proper when IBD makes sufferers feel very ill with abdominal pain, urgency, diarrhoea, faecal incontinence, weight loss, rectal bleeding, intestinal fistulae, bowel obstruction, or abdominal sepsis, and who often require mutilating surgery for a chronic incurable relapsing condition which is no fault of their own.

In contrast, there is radiation induced bowel damage. In the UK, 6000 individuals annually will be left with lower gastrointestinal symptoms affecting quality of life which include feeling very ill with abdominal pain, urgency, diarrhoea, faecal incontinence ..... -yes, identical symptoms-and at the BSG meeting this year there was one 15 minute presentation related to radiation induced bowel problems. There are no dedicated research funds or support groups to help these patients.

In the UK, 12000 individuals are treated with radical radiotherapy for pelvic cancer annually, mostly with curative intent. Figures for the rest of the Western world are not available but probably amount to 150000 in total. Radical therapy (which is increasingly successful ${ }^{3}$ ) aims to cure the patient of their cancer but carries a risk for normal tissues around the tumour. During their five or six week course of treatment, approximately $80 \%$ of patients will develop gastrointestinal symptoms which are partly caused by acute gastrointestinal inflammation. It is very rare, even as a gastroenterologist working within a cancer centre, to be asked to see a patient with acute radiation toxicity.

"In the UK, 12000 individuals are treated with radical radiotherapy for pelvic cancer annually, mostly with curative intent"

Conventional wisdom states that these acute symptoms will settle within three months (I believe this is far from universal) and symptoms persisting at that time, or arising subsequently, are deemed to be late toxic effects. Unlike the patient with IBD who will visit a specialist or general practitioner seven times in the first year of their diagnosis, ${ }^{2}$ it is also unusual for a gastroenterologist to be asked to see these patients with late radiation toxicity. The best data we have suggest that only $20 \%$ will ever get referred to a gastroenterologist ${ }^{5}$ and very few gastroenterologists feel confident in managing these patients. There are many reasons for this low rate of referral. Most patients fail to report symptoms to their oncologists until severe complications occur. ${ }^{6}$ Patients often believe that their symptoms are the inevitable consequences of radiotherapy treatment, of being old, or that there is nothing that can be done, ${ }^{7}$ while others believe there are more important issues to discuss in the limited time available. ${ }^{8}$ Many oncologists may also believe that there is little that can be done and thus identification of chronic gastrointestinal symptoms is essentially futile.

There are two types of problems that develop. There are those which are life threatening: fistulation, sepsis, stenosis, intestinal failure, perforation, transfusion dependent bleeding, or 
Table 1 Causes of diarrhoea after radiotherapy: the published data

\begin{tabular}{|c|c|c|c|}
\hline & $\begin{array}{l}\text { Ludgate }^{34} \\
(n=26)\end{array}$ & $\begin{array}{l}\text { Danielsson }^{35} \\
(\mathrm{n}=20)\end{array}$ & $\begin{array}{l}\text { Andreyev }^{25} \\
(\mathrm{n}=78)\end{array}$ \\
\hline Bile salt diarrhoea & $50 \%$ & $65 \%$ & $1 \%$ \\
\hline Large bowel strictures & $15 \%$ & - & $3 \%$ \\
\hline Vitamin B12 deficiency & $11 \%$ & $30 \%$ & $14 \%$ \\
\hline Bacterial overgrowth & $8 \%$ & $45 \%$ & $12 \%$ \\
\hline Diverticular disease & $8 \%$ & - & $22 \%$ \\
\hline Relapse of primary cancer & $4 \%$ & - & $10 \%$ \\
\hline Pelvic sepsis & $4 \%$ & - & $3 \%$ \\
\hline New GI neoplasia & - & - & $8 \%$ \\
\hline Drug related & - & - & $5 \%$ \\
\hline $\mathrm{IBD}$ & & & $4 \%$ \\
\hline Proctitis & & & $33 \%$ \\
\hline Other & & & $5 \%$ \\
\hline
\end{tabular}

secondary cancer. We do not know how often these occurand they are not really in the province of the gastroenterologist-but the best estimates put these side effects of treatment at $4-8 \%$ after $5-10$ years. ${ }^{9}{ }^{10}$

More common, although less recognised, are chronic gastrointestinal symptoms: $80 \%$ of all treated patients will notice a permanent change in the way their bowels behave after radiotherapy. ${ }^{8}$ As long as the patient is warned in advance, this is unimportant unless that change in their bowels affects quality of life.

Reports suggest that between $6 \%$ and $78 \%$ of long term survivors have gastrointestinal symptoms affecting quality of life $\mathrm{e}^{11}{ }^{12}$ but most studies use inadequate and poorly validated assessments of gastrointestinal toxicity and cannot be accepted at face value. ${ }^{13}$ When studies are reduced to those which have assessed gastrointestinal toxicity as a primary end point using robust methodology, a realistic estimate seems to be that $50 \%$ of patients are left with long term chronic gastrointestinal side effects affecting quality of life. $^{8}{ }^{14-17}$ The frequency of significant problems may be slightly higher in gynaecological and bladder cancer patients (because of the volume of bowel irradiated) and in rectal patients (because of compounding effects of surgery) than prostate patients, but late gastrointestinal toxicity is not entirely related to the dose of radiotherapy delivered and depends on a complex interaction of physical, patient related, treatment, and genetic factors which have been very poorly characterised.

\section{"Reports suggest that between $6 \%$ and $78 \%$ of long term survivors have gastrointestinal symptoms affecting quality of life"}

The precise sequence of pathological changes which lead to those symptoms is also largely unexplored. This is despite radiation induced bowel damage being an excellent model of disease development within the human bowel. Most gynaecology and urology patients will have normal gastrointestinal tracts before treatment. The time of the first insult is known in advance and the subsequent pathological process may have parallels with other gastrointestinal diseases. Yet even the histological changes to the human rectal mucosa after radiotherapy were not fully described by the five small studies $^{18-22}$ which have been undertaken. Within two weeks of starting pelvic radiotherapy, maximal rectal histological changes are present but despite continuing radiotherapy may improve a little over the next four weeks. It is not known how these changes develop over the first two weeks. It is not know which (if any) early changes predispose to significant late change. There are virtually no data exploring why or how the acute inflammatory response to radiotherapy characterised by eosinophils, transforms to a chronic fibrotic response with minimal inflammatory components. We know virtually nothing about which cytokines drive the inflammatory or fibrotic reactions or which cell types produce these cytokines or how apoptotic cell products, pathogenic bacteria, macrophages, mast cells, T cell subset responses, or whatever, interact to perpetuate it. More detailed data on cytokine changes from animal experiments are available but unfortunately these are very unhelpful as different animal models respond quite differently to identical irradiation. ${ }^{23}$

Yet despite an incomplete understanding of the pathology underlying symptoms in IBD, we still see these patients and offer them treatment-albeit not always to good effect. So, should we not try to do the same for symptoms affecting patients after pelvic radiotherapy? Of all the problems which can arise, new bowel symptoms have the greatest impact on quality of life. ${ }^{24}$ In addition, most have been cured of their cancer and many are young. Of the first 265 such patients that I saw-not an atypical cohort-age ranged from 22 to 85 years, with almost half of the women under the age of 60 years. Even if a patient is not so young, they still generally represent the fitter end of the spectrum for their age because they have been selected for-and survived-radical therapies.

\section{"Half of all patients treated with pelvic radiotherapy are troubled by diarrhoea or constipation"}

Half of all patients treated with pelvic radiotherapy are troubled by diarrhoea or constipation. ${ }^{8}$ The causes of constipation have not been investigated. The causes of diarrhoea are many and include accelerated small and large bowel transit, bacterial overgrowth, malabsorption of bile salts, medication, primary fatty acids or carbohydrates, pancreatic insufficiency, physiological changes to the lower gastrointestinal tract, stricture formation, and psychological factors. In addition, radiotherapy may exacerbate pre-existing IBD and induce microscopic colitis. Some of these are clearly curable with simple treatments, so it may be helpful to know the relative importance of any of these causes, but there are virtually no data. Two small studies (and most textbooks) have suggested that bile salt malabsorption is the most important culprit but our data ${ }^{25}$ suggest different conclusions (table 1).

One in five patients has faecal incontinence after radiotherapy which affects their quality of life. ${ }^{8}$ Most radiotherapists do not believe this finding. This is because the widely used RTOG scoring system used in most trials to 
Table 2 Outcome from flexible endoscopic evaluation of rectal bleeding after pelvic radiation: the published data

\begin{tabular}{|c|c|c|}
\hline Study & $\begin{array}{l}\text { No of } \\
\text { patients }\end{array}$ & Main conclusion of endoscopic investigation \\
\hline $\begin{array}{l}\text { Reichelderfer }^{36} \\
\text { Den Hartog Jager }^{37} \\
\text { Hu }^{38} \\
\text { Moore }^{39} \\
\text { Wachter }^{40} \\
\text { Williams }^{41}\end{array}$ & $\begin{array}{r}13 \\
90 \\
19 \\
26 \\
44 \\
171\end{array}$ & $\begin{array}{l}\text { - Colonoscopy changes management } \\
25 \% \text { of findings are unrelated to previous radiotherapy } \\
\text { - Waste of time } \\
\text { - } 65 \% \text { of findings are unrelated to previous radiotherapy } \\
\text { - } 33 \% \text { of findings are unrelated to previous radiotherapy } \\
\text { - Symptoms do not reliably indicate the underlying diagnosis }\end{array}$ \\
\hline
\end{tabular}

document toxicity from radiotherapy asks no questions about anorectal symptoms. Therefore, faecal incontinence is rarely identified ${ }^{26}$ In addition, we know that patients will often not confess even to gastroenterologists that they are faecally incontinent, so it is even rarer for them to tell oncologists. Yet there is evidence that of all the gastrointestinal symptoms which can occur after radiotherapy, faecal incontinence causes the greatest distress. ${ }^{27-29}$ So, it is sobering that until this year ${ }^{30}$ there has not been a single published study of any form of medical treatment for faecal incontinence in this population. However, my uncontrolled observation (currently being tested in a randomised trial) is that simple interventions produce substantial and sustained benefit in many patients.

Our data suggest that abdominal, perineal, or back pain affecting quality of life occurs in 1 in 10 patients. ${ }^{8}$ We have also shown that pain is unlikely in the presence of straightforward radiation proctitis (even the terminology is wrong, it is proctopathy not proctitis, enteropathy not enteritis, inflammation is not prominent within a short time of completing treatment) but there is no other research into the cause for this pain. I believe that abdominal pain is commonly due to colonic loading and spasm-if correct, both very treatable. I have found magnetic resonance imaging helpful in identifying those with occult infection causing perineal pain ( $1 \%$ of my patient group). New onset lower back pain often has a sinister cause.

One in 20 patients will have rectal bleeding affecting quality of life. ${ }^{8}$ More than $25 \%$ of rectal bleeding after radiotherapy is not due to radiation proctitis (table 2 ) and symptoms are an unreliable predictor of the underlying diagnosis, yet few radiotherapy units routinely refer their patients for a flexible sigmoidoscopic evaluation of new onset rectal bleeding.

\section{"Our understanding of how to treat these patients is equally dismally lacking an evidence base"}

Our understanding of how to treat these patients is equally dismally lacking an evidence base. ${ }^{31}$ Indeed, I believe some treatments used are often potentially dangerous (for example, argon beam ablation of ischaemic, bleeding mucosa-it has a $15 \%$ serious complication rate in the published literature). Perhaps it is even a good thing that many therapeutic trials have not been performed for "radiation enteritis" or "radiation proctitis"; on their own, they are not robust labels and should be abandoned. We have described how most patients have more than one diagnosis contributing to their symptoms. ${ }^{25}$ An extreme example is patients who present with steatorrhoea. I have three patients with pancreatic insufficiency (treated with enzyme supplements) and recurrent bacterial overgrowth (requiring cyclical antibiotics) and fatty acid malabsorption (treated with a $40 \mathrm{~g}$ fat diet) and bile salt malabsorption (treated with bile binders), all caused by radiotherapy, but the steatorrhoea will not settle until all causes have been treated.

Despite-or perhaps because of-the lack of data, I am extremely optimistic about the future. Fibrosis seems to be the unifying underlying cause for most symptoms. Reversal of fibrosis, or its prevention at an early stage, could be highly profitable. There is an excitingly vast array of agents with antifibrotic potential. The best characterised compounds for soft tissue radiation injury outside the bowel are liposomal $\mathrm{Cu} / \mathrm{Zn}$ superoxide dismutase $\mathrm{e}^{32}$ and pentoxifylline with high dose vitamin $\mathrm{E}^{33}$ Other possible agents include interferon alpha or gamma, colchicine, tumour necrosis factor $\alpha$ antagonists, antibodies to integrins, angiotensin converting enzyme inhibitors, anti-endothelin-1 antagonists, transforming growth factor $\beta$ neutralising antibodies, and platelet derived growth factor inhibitor. Progress in understanding the development and treatment of fibrosis in these patients might have important consequences for patients with other causes for fibrosis in the gastrointestinal tract: Crohn's disease, scleroderma, ischaemic colitis, pouch fibrosis.....

\section{"What we have still failed to address systematically is how best to care for the patient who is cured of their cancer but living with the physical consequences"}

Gastroenterologists say that these patients are rarely referred by radiotherapists. Radiotherapists suggest that referral to gastroenterologists rarely leads to timely and constructive interventions. Patients often indicate that neither group show much interest in their symptoms. We are becoming increasingly good at knowing how to cure cancer. Mechanisms exist to address the psychological struggles of patients with and after cancer. The hospice movement has revolutionised the care of those dying from cancer. What we have still failed to address systematically is how best to care for the patient who is cured of their cancer but living with the physical consequences. Radiotherapy is forever! There is so much to do.

Conflict of interest: None declared.

\section{REFERENCES}

1 Logan R. Inflammatory bowel disease incidence: up, down or unchanged? Gut 1998:42:309-11.

2 Rubin G, Hungin A, Kelly P, et al. Inflammatory bowel disease: epidemiology and management in an English general practice population. Aliment Pharmacol Ther 2000;14:1553-9.

3 UKCCCR Anal Cancer Trial Working Party, UK Co-ordinating Committee on Cancer Research. Epidermoid anal cancer: results from the UKCCCR randomised trial of radiotherapy alone versus radiotherapy, 5-fluorouracil, and mitomycin. Lancet 1996;19:1049-54.

4 Thomas G. Concurrent chemotherapy and radiation for locally advanced cervical cancer: the new standard of care. Semin Radiat Oncol 2000; 10:44-50.

5 Andreyev HJN, Amin Z, Blake P, et al. Gl symptoms developing after pelvic radiotherapy require gastroenterological review but is that happening in the UK? Clin Oncol 2003;15:S12. 
6 Yeoh E, Horowitz M. Radiation enteritis. Surg Gynecol Obstet 1987; 165:373-9.

7 Faithfull S. 'Just grin and bear it and hope that it will go away': coping with urinary symptoms from pelvic radiotherapy. Eur J Cancer Care Engl 1995:4:158-65.

8 Gami B, Harrington K, Blake $P$, et al. How patients manage gastrointestinal symptoms after pelvic radiotherapy. Aliment Pharmacol Ther 2003; 18:987-94.

9 Denton A, Bond S, Matthews S, et al. National audit of the management and outcome of carcinoma of the cervix treated with radiotherapy in 1993. Clin Oncol (R Coll Radiol) 2000;12:347-53.

10 Nostrant T. Radiation injury. In: Yamada T, Alpers D, Owyang C, et al, eds. In: Textbook of gastroenterology, 3rd edn. Philadelphia: JB Lippencott, 2000:2605-16.

11 Potosky A, Legler J, Albertsen P, et al. Health outcomes after prostatectomy or radiotherapy for prostate cancer: results from the prostate cancer outcomes study. J Natl Cancer Inst 2000;92:1582-92.

12 Kollmorgen C, Meagher A, Wolff B, et al. The long-term effect of adjuvant post-operative chemoradiotherapy for rectal carcinoma on bowel function. Ann Surg 1994;220:676-82.

13 Yeoh E, Botten R, Russo A, et al. Chronic effects of therapeutic irradiation for localised prostatic carcinoma on anorectal function. Int J Radiation Oncology Biol Phys 2000;47:915-24.

14 Lundby L, Jensen V, Overgaard J, et al. Long-term colorectal function after postoperative radiotherapy for colorectal cancer. Lancet 1997;350:564.

15 Dahlberg M, Glimelius B, Graf W, et al. Preoperative irradiation affects functional results after surgery for rectal cancer. Dis Colon Rectum 1998:41:543-51.

16 Olopade F, Blake P, Dearnaley D, et al. The inflammatory bowel disease questionnaire and the Vaizey incontinence questionnaire are useful to identify gastrointestinal toxicity after pelvic radiotherapy. Radiother Oncol 2004;73(suppl 1):S382

17 Kozelsky T, Meyers G, Sloan J, et al. Phase III double-blind study of glutamine versus placebo for the prevention of acute diarrhea in patients receiving pelvic radiation therapy. J Clin Oncol 2003;21:1669-74.

18 Gelfand $M$, Tepper $M$, Katz $L$, et al. Acute radiation proctitis in man. Gastroenterology 1968;54:401-11

19 Hasleton P, Carr N, Schofield P. Vascular changes in radiation bowel disease. Histopathology 1985;9:517-34.

20 Haboubi N, Schofield P, Rowland P. The light and electron microscopic features of early and late phase radiation induced proctitis. Am J Gastroenterol 1988:83:1140-4.

21 Sedgewick D, Howard G, Ferguson A. Pathogenesis of acute radiation injury in the rectum. Int I Colorectal Dis 1994;9:23-30.

22 Hovdenak N, Fajardo L, Haver-Jensen M. Acute radiation proctitis: a sequential clinicopathologic study during pelvic radiotherapy. Int J Rad Oncol Biol Phys 2000;48:1111-17.

23 Skwarchuk M, Travis E. Changes in histology and fibrogenic cytokines in irradiated colorectum of two murine strains. Int J Radiat Oncol Biol Phys 1998:42:169-78.
24 Bacon C, Giovannucci E, Testa M, et al. The association of treatment-related symptoms with quality-of-life outcomes for localized prostate carcinoma patients. Cancer 2002;94:862-71.

25 Andreyev HJN, Vlavianos P, Blake P, et al. Gastrointestinal symptoms after pelvic radiotherapy: is there any role for the gastroenterologist? Int J Rad Biol Phys 2005 (in press).

26 Putta S, Andreyev HJN. Faecal incontinence-a late side effect of pelvic radiotherapy. Clin Oncol 2005 (in press).

27 al-Abany M, Helgason A, Cronqvist A, et al. Long-term symptoms after external beam radiation therapy for prostate cancer with three or four fields. Acta Oncol 2002;41:532-42.

28 Henningsohn L, Wijkstrom H, Dickman $\mathrm{P}$, et al. Distressful symptoms after radical radiotherapy for urinary bladder cancer. Radiother Oncol 2002;62:215-25

29 Bergmark K, Avall-Lundqvist E, Dickman P, et al. Patient-rating of distressful symptoms after treatment for early cervical cancer. Acta Obstet Gynecol Scand 2002:81:443-50.

30 Badvie S, Andreyev HJN. Topical phenylephrine in the treatment of radiationinduced faecal incontinence. Clin Oncology 2005;17:122-6.

31 Denton A, Andreyev HJN, Forbes A, et al. Systematic review for non-surgical interventions for the management of late radiation proctitis. Br J Cancer 2002;87:134-43

32 Delanian S, Baillet F, Huart J, et al. Successful treatment of radiation-induced fibrosis using liposomal Cu/Zn superoxide dismutase: clinical trial. Radiother Oncol 1994:32:12-20.

33 Delanian S, Porcher R, Balla-Mekias S, et al. Randomized, placebo-controlled trial of combined pentoxifylline and tocopherol for regression of superficial radiation-induced fibrosis. J Clin Oncol 2003;21:2545-50.

34 Ludgate S, Merrick M. The pathogenesis of post-irradiation chronic diarrhoea: measurement of SeHCAT and B12 absorption for differential diagnosis determines treatment. Clin Radiol 1985;36:275-8.

35 Danielsson A, Nyhlin $\mathrm{H}$, Persson $\mathrm{H}$, et al. Chronic diarrhoea after radiotherapy for gynaecological cancer: occurrence and aetiology. Gut 1991:32:1180-7.

36 Reichelderfer M, Morrissey J. Colonoscopy in radiation colitis. Gastrointest Endosc 1980;26:41-3.

37 Den Hartog Jager F, van Haastert M, Batterman J, et al. The endoscopic spectrum of late radiation damage of the recto-sigmoid colon. Endoscopy $1985 ; 17: 214-16$

38 Hu K, Wallner K. Clinical course of rectal bleeding following 1-125 prostate brachytherapy. Int J Radiat Oncol Biol Phys 1998:41:263-5.

39 Moore E, Magrino T, Johnstone P. Rectal bleeding after radiation therapy for prostate cancer: endoscopic evaluation. Radiology 2000;217:215-18.

40 Wachter S, Gerstner N, Goldner G, et al. Endoscopic scoring of late rectal mucosal damage after conformal radiotherapy for prostatic carcinoma. Radiother Oncol 2000:54:11-19.

41 Williams HRT, Vlavianos P, Blake P, et al. The significance of rectal bleeding after pelvic radiotherapy. Aliment Pharmacol Ther 2005;21:1085-90.

\section{Call for papers}

11 th European Forum on Quality Improvement in Health Care 26-28 April 2006, Prague, Czech Republic

Deadline 30 September 2005.

For further information and to submit online go to: www.quality.bmipg.com 